\title{
National Center for Complementary and Alternative Medicine
}

National Cancer Institute

\section{Source}

National Cancer Institute. National Center for Complementary and Alternative Medicine. NCI Thesaurus. Code C19897.

A center within the National Institutes of Health that acts as the Federal Government's lead agency for scientific research on the diverse medical and health care systems, practices, and products that are not generally considered part of conventional medicine. 